\title{
CONSUMER PERCEPTION OF KAROO LAMB AS A PRODUCT OF ORIGIN AND THEIR CONSEQUENT WILLINGNESS TO PURCHASE
}

\author{
Tessa Weissnar \\ University of Pretoria, South Africa \\ Dr Gerrie du Rand \\ University of Pretoria, South Africa
}

Keywords: Karoo lamb, perceptions, product of origin, means-end chain, association pattern technique (APT), willingness to purchase, local food

\begin{abstract}
Consumers are increasingly concerned to know where food comes from and how it is produced. Since South African lamb is usually produced on natural pastures and in arid areas, certain breeds have been specifically bred for arid areas, such as the Karoo region, renowned for its high quality lamb. Consumer's perceptions of Karoo lamb (bred in the Karoo region) and non-Karoo lamb (bred on other areas in South Africa) were studied using meansend chain theory, focusing on the association pattern technique (APT). The main aim of the study was to determine consumer's perceptions of Karoo lamb as a product of origin and furthermore to determine consumer's willingness to purchase product of origin. The motivational structures show perceived differences between Karoo and non-Karoo lamb consumers. Karoo lamb is preferred mainly due to its brand which signifies confidence in local produce, its taste and high quality. Non-Karoo lamb was seen as good value for money that satisfies the required values of consumers not interested in knowing the origin. Results suggest that consumers are willing to pay a premium for product of origin.
\end{abstract}

\section{Introduction}

South Africa has an abundance of resources that merit not only international recognition, but at a regional level too. There has been an increase in international protection of resources, but what about South Africa as a developing country? The Karoo has become known for its distinctive produce and has acquired a consequent reputation for it. The fact that this acquired reputation may be scrutinized by others to benefit from the reputation warrants seeking 
protection. The issue of Geographic Indications has been around for many years, however, has only really been established in the wine industry within South Africa. Consequently, finding out whether a country or origin label is warranted within the food industry, particularly with regard to Karoo lamb is necessary, and, consequently, will consumers be willing to pay for the security of a name?

The theory underlying consumer perception lies in the understanding of consumer behaviour. Gutman's means-end theory, established in 1982, is widely advocated for understanding linkages between values and consumer behaviour. Association Pattern Technique (APT) was developed in order to get a quantitative description of consumer's motivational structures (Feunekes \& den Hoed, 2001:1). This method was utilised to understand what makes consumers motivated to choose specific product, in particular Karoo lamb perceptions.

\section{Materials and methods}

\subsection{Means-end chain}

Gutman (1982) introduced the means-end chain (MEC) into the field of marketing and consumer research. He proposed the means-end chain as a way of explaining the relationship between consumer knowledge and consumer behaviour. MEC is therefore a cognitive structure that links consumer's knowledge of products to their knowledge of certain consequences and values connected with those products (Ter Hofstede, Audenaert, Steenkamo \& Wedel. 1998). In this theory, products are seen as means through which consumers obtain certain value ends. It recognises that consumers do not want products for their own sake, but for what the product can do for, and provide them (Feunekes \& den Hoed, 2001:1). Typically, means-end chains have been used to describe consumer's product and brand perceptions.

The conceptual model of MEC theory specifies that the consumers' subjective knowledge about product categories is stored in associative networks that are organized as means-end chains. The key constructs in these networks are attributes, consequences and values. 
Attributes are properties of a product that can be sensed, i.e. products that have a particular form, colour, smell, taste, sound etc. Benefits refer to what the product is perceived as doing for or providing to the consumer. Values are intangible, higher order outcomes or end-states of the consumer (Feunekes \& den Hoed, 2001:1).

Each of the key constructs may be split in two levels to allow a more detailed analysis of consumer knowledge structures; concrete and abstract attributes, functional and psychosocial consequences, and instrumental and terminal values, as is illustrated in figure 1 (Olson \& Reynolds. 1983). Concrete attributes represent tangible, physical characteristics of the product, while abstract attributes represent intangible, subjective characteristics. Functional consequences are directly experienced, tangible outcomes of product use, while psychosocial consequnecs are more personal and less tangible outcomes. Instrumental values are the cognitive representations of preferred modes of conduct or behaviour. Terminal values represent preferred end-states of being (Peter and Olson, 1993). These constructs were untilised in determining the perceptions of consumers regarding Karoo lamb.

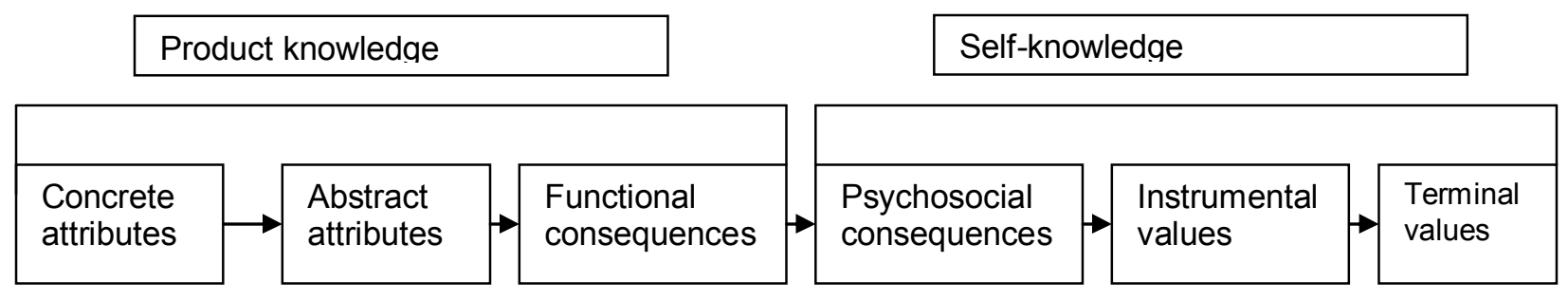

Figure 1: Means-end chains connect product knowledge to self-knowledge

MEC theory suggests that product knowledge in consumers is hierarchically organized by level of abstraction. The higher the level of abstraction, the stronger and more direct the relationship with the person (Olson \& Reynolds. 1983).

\subsection{Association pattern technique (APT)}

Association Pattern Technique (APT) is based on means-end theory (Feunekes \& den Hoed, 2001:1). APT is a quantitative data collection technique, in which a fixed format is used where links between attributes and consequences and links between consequences and values are 
measured separately (Ter Hofstede, Audenaert, Steenkamp \& Wedel, 1998:38). This study, utilised means-end chain theory as the basis methodology, whereby APT was the main data collection method, measuring consumers perceptions at a higher level of abstraction, however, utilising the quantitative properties of APT.

APT is cheaper and faster than laddering, even though the laddering technique is the most popular means-end theory collection method. However, it was found that laddering is very time-consuming, costly and requires highly trained interviewers.

The results obtained from means-end chain and APT can be utilised to create a hierarchical value map (HVM) which is a graphic representation of the most frequently mentioned associations between categories of attributes, consequences and values (Nielsen, BechLarsen \& Grunert. 1998: 456. Reynolds \& Gutman. 1998.11).

\subsection{Van Westendorp's technique - Willingness to purchase}

Knowing the price sensitivity by level of current and potetntial customers is crucial. Knowing the price sensitivity by level of product usage is a prerequisite to minimizing the risks which occur when prices are changed (Draeger, 2009:21). Peter van Westendorp's Price Sensitivity Measurement Model (PSMM) consists of three parts. The first is the product description. Second, a price scale with at least 15 evenly spaced increments is given to respondents to use when they answer the questions. The final part of the PSMM consists of for simple questions about the price of the product or service. These four questions include (Draeger, R \& Perham, K, 2009:19):

1. At what price on the scale would you consider the product or service to be expensive?

2. At what price on the scale would you consider the product or service to be cheap?

3. At what price would you consider the product or service to be so expensive that it is beyond you considering buying?

4. At what price do you consider the product or service to be so cheap that you would question the quality? 
Upon completion of the questions, the analysis is done by graphing the cumulative percentage of respondents for each of the four questions (on the y axis) against the price scale shown to the respondents ( $x$ axis). The price that the market anticipates to pay for the product or service is determined where an equal proportion of respondents say the price is "cheap" and “expensive” (Draeger, 2009:21; Draeger \& Perham, 2009: 19).

\section{The objectives of this study include:}

1. To establish consumer's behaviour in terms of identifying their perceptions of Karoo lamb.

2. To establish how and why product of origin influences consumer's perception of a product such as Karoo lamb.

a. To identify the consequences related to the attributes selected by consumers regarding Karoo lamb linked to the production origin of the meat.

b. To determine the relevant values of consumers regarding Karoo lamb linked to the production origin of the meat.

3. To establish the probability of purchase regarding Karoo lamb with a origin status.

a. To determine the optimal price that Karoo lamb can be sold at linked to origin status and their probably be purchased.

4. To contribute to the preparation of information required for the submission of Geographic Indications for Karoo lamb.

a. To compile a report verifying consumer's perception, awareness and degree of liking regarding Karoo lamb.

\section{$3 \quad$ Results and discussion}

Data was collected in two phases for the purpose of triangulation and to enhance the authenticity of the data. The first phase utilized focus groups to elicit the most important attributes, consequences and values for the APT questionnaire, on the ground of Karoo lamb. The second phase included a survey (sent via email), utilising the APT questionnaire (determining consumer perceptions) and Van Westendorp's price sensitivity (determining 
willingness to purchase). Hierarchical Value Maps were then generated from the data obtained in the APT questionnaire.

A total of 276 surveys were completed via email and facilitated by Consulta research South Africa. The sample consisted of members of the database of Karoo initiative and Consulta research database, which consisted of age groups 25-60 years, male and female, of which $65 \%$ of the sample fell into the high LSM group (8-10). Hierarchical Value Maps (HVM) were utilized as a visual method of analyzing the data obtained from means-end chains.

\subsection{Focus groups}

Due to the fixed nature of APT, the various attributes, consequences and values needed to be discovered. These attributes, consequences and values can be obtained as a secondary source, from literature or from a primary source being the consumer. In order to obtain the attributes, consequences and values that consumers associate with Karoo lamb, a series of focus group discussions were held. In total, three focus groups were held, consisting of 7 participants each. Each participant was screened beforehand to ensure they were consumers of lamb (at least once a month), within the LSM groups 7 to 10 and between the ages of 25-55, as these are the South African consumers that consume lamb on a regular basis. Gender and race were not considered as important factors, as consumers of lamb range from both genders and most races. (BFAP Baseline 2007:49).

A pilot focus group was initially conducted in order to ensure that constructs relating to attributes, consequences and values were correct and probing techniques to elicit attributes, consequences and values sufficient in order to uncover reasons as to why consumers purchase Karoo lamb. Direct elicitation was used to find the starting point of the focus group discussions. For example, participants were asked to list the attributes most important to them when purchasing Karoo lamb and then probed with "and WHY would that attribute be important". This elicitation was continued until the participants could give no further explanation as to WHY certain attributes, consequences and values were important and thereby a ladder was constructed. 
Upon transcribing results, the focus group discussions elicited a total of 12 attributes, 17 consequences and 6 values. By grouping similar attributes, consequences and values that signified a similar meaning, as well as consulting with previous literature, the constructs for the fixed association pattern technique questionnaire were fixed and the second phase of the study could take place.

\subsection{Association Pattern Technique}

Before commencing with the questionnaire, respondents were asked to indicate their preference for Karoo Lamb by selecting the most appropriate category stating 'I never buy, prepare or eat Karoo Lamb' or 'I prefer to buy, prepare and eat Karoo Lamb'. By segmenting the consumers into a 'Karoo lamb' and 'Non-Karoo lamb' group, perceptions could be deduced by comparing the two groups and highlighting the main differences in order to deduce a meaningful conclusion.

The most mentioned associations were summarised and illustrated in figure's 2 and 3 . As previously mentioned, the APT questionnaire was completed by 276 respondents, of which 219 participants $(79 \%)$ indicated that, if given the choice, they preferred to consume Karoo lamb, whereas 57 participants $(21 \%)$ had no specific origin preference.

In APT analysis, Figure 2 indicates the perception of consumers regarding the relationship between the physical attributes of lamb and the consequences related to the use of the 'product'. Figure 3 indicates perception regarding the relationship between the use of the product and the emotional needs attached. 


\begin{tabular}{|c|c|c|}
\hline \multicolumn{3}{|c|}{ A-C MATRIX } \\
\hline & $\begin{array}{l}\text { Karoo } \\
(n=219)\end{array}$ & $\begin{array}{l}\text { Non-Karoo } \\
(n=57)\end{array}$ \\
\hline Price & $\begin{array}{l}\text { Quality indicator } \\
23.6 \%\end{array}$ & $\begin{array}{l}\text { Good value for } \\
\text { money } \\
33.3 \%\end{array}$ \\
\hline Image & $\begin{array}{l}\text { Quality } \\
21.4 \%\end{array}$ & $\begin{array}{l}\text { No health risk } \\
6.5 \%\end{array}$ \\
\hline Brand & $\begin{array}{l}\text { Confidence in local } \\
\text { produce } \\
16.6 \% \\
\end{array}$ & $\begin{array}{l}\text { It is a quality product } \\
22.9 \%\end{array}$ \\
\hline Origin & $\begin{array}{l}\text { Confidence in local } \\
\text { produce } \\
20.4 \%\end{array}$ & $\begin{array}{l}\text { Confidence in local } \\
\text { produce } \\
27.4 \%\end{array}$ \\
\hline
\end{tabular}

Figure 2: A-C Matrix (APT analysis)

Price and quality has been well researched over the years, where a higher price is usually seen as indicating a higher quality product. Regarding perceptions of the attribute of price with Karoo lamb consumers, this price-quality relationship was found to be important. In contrast, by not stating an origin, consumers view that non-Karoo lamb indicates that the product is value for money, thereby a major motivating factor for not purchasing based on origin status.

Therefore, with research, food quality is seen as 'subjective quality' or 'perceived quality' as consumers form subject impressions of the quality based on psychological processes that are influenced by the level of previous knowledge and cognitive competencies of each consumer (Hansen, 2005:501; Bredahl, 2003:65).

Where credence attributes play an important role, it is useful to extend the analysis beyond product attributes to explore aspects of a more emotional nature that might be influencing consumers (Barrena \& Sanchez, 2009: 145). Image is seen as a credence attribute and it is evident that consumers of Karoo lamb feel that the consumption of the Karoo lamb portrays and image of a quality product and in contrast, consumer of non-Karoo lamb view the credence attribute of image to hold no health risk regarding its consumption. Exploring this credence attribute of image may be useful in terms of marketing of Karoo lamb to consumers who regard this attribute as important. 
The brand of Karoo lamb was found to be linked to the consequence of having confidence in local produce. In a study conducted by Lind (2007) it was found that domestic origin was foremost believed to imply good quality and health. And by having confidence in local produce, Karoo lamb can be useful in portraying quality linked to a proudly South African brand whereby origin status is key. Non-Karoo lamb consumers linked brand of non-origin status to high quality. This statement is quite a contradiction to the study conducted by Lind indicating a linkage between domestic origin and good quality. However, perhaps a link to South African lamb, regardless of region of origin still signifies good quality relating purely to domestic origin. This point is evident in the fact that consumers viewed origin status as confidence in local produce, containing a specific region origin status or not, however signifying a proudly South African connotation.

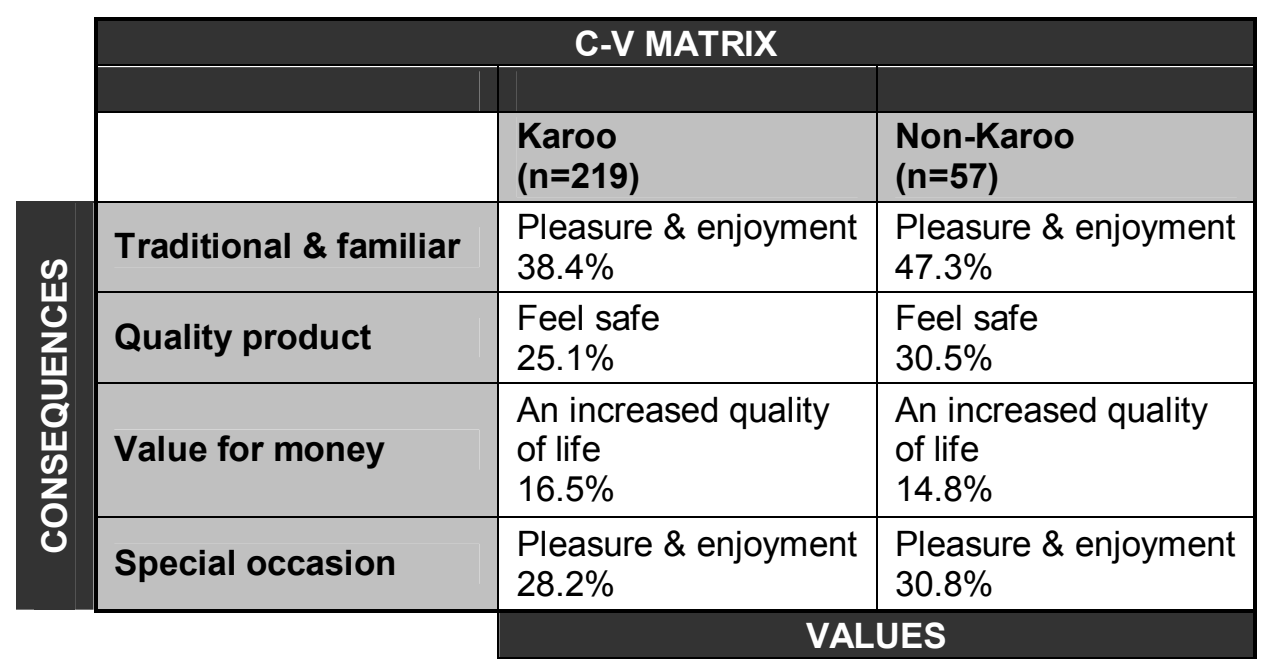

Figure 3: $\quad$ C-V Matrix (APT analysis)

A clear difference between Karoo and non-Karoo lamb consumers is evident in figure 2 (A-C matrix), however minimal differences were found in the C-V matrix (figure 3). All of the most mentioned linkages between consequences and values indicated similar end-states (values). This illustrates that physical properties of Karoo lamb (the visible attributes) are important to consumers; however, at a higher level of abstraction (emotionally), the origin becomes less 
important. The purchase of meat has been linked to a 'think' product. 'Think' products are mainly bought for utilitarian reasons, the decision being locally processed and the focus on the functional performance. Chains for 'think' products will stop at lower levels of abstraction and have higher elicitation ratings for levels related to product knowledge (attributes and functional consequences) (Lind 2007, 692). This theory on 'think' products could be linked to the reason as to why, at a higher level of abstraction, the distinction between Karoo and non-Karoo becomes less important. This finding could be critical to successful marketing of Karoo lamb, whereby the attributes highlighting Karoo lamb need to be used to influence the consumer to purchase the product.

\subsection{Van Westendorp's price sensitivity}

In the APT questionnaire, consumers were asked the four fundamental questions of Van Westendorp in order to determine price sensitivity regarding origin status.

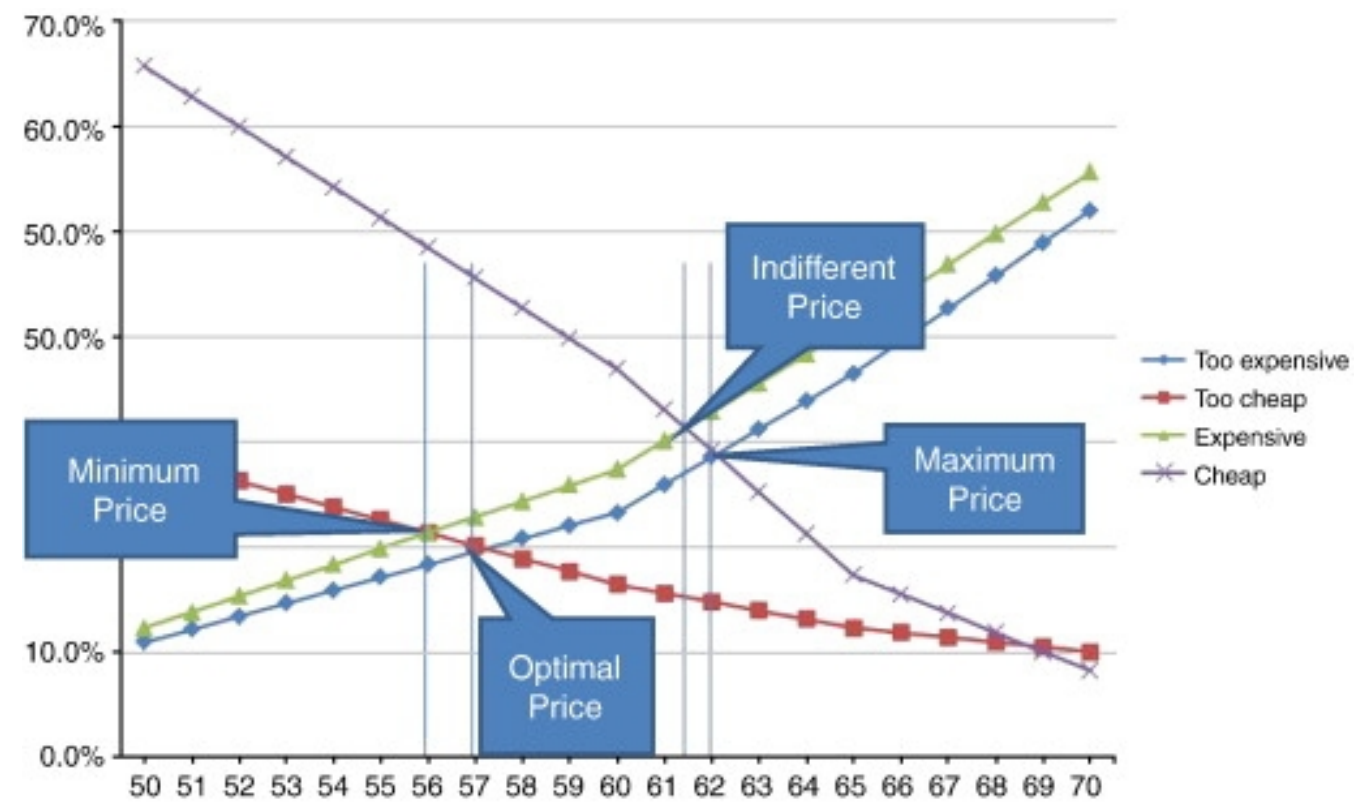

Figure 4: Karoo lamb price sensitivity 


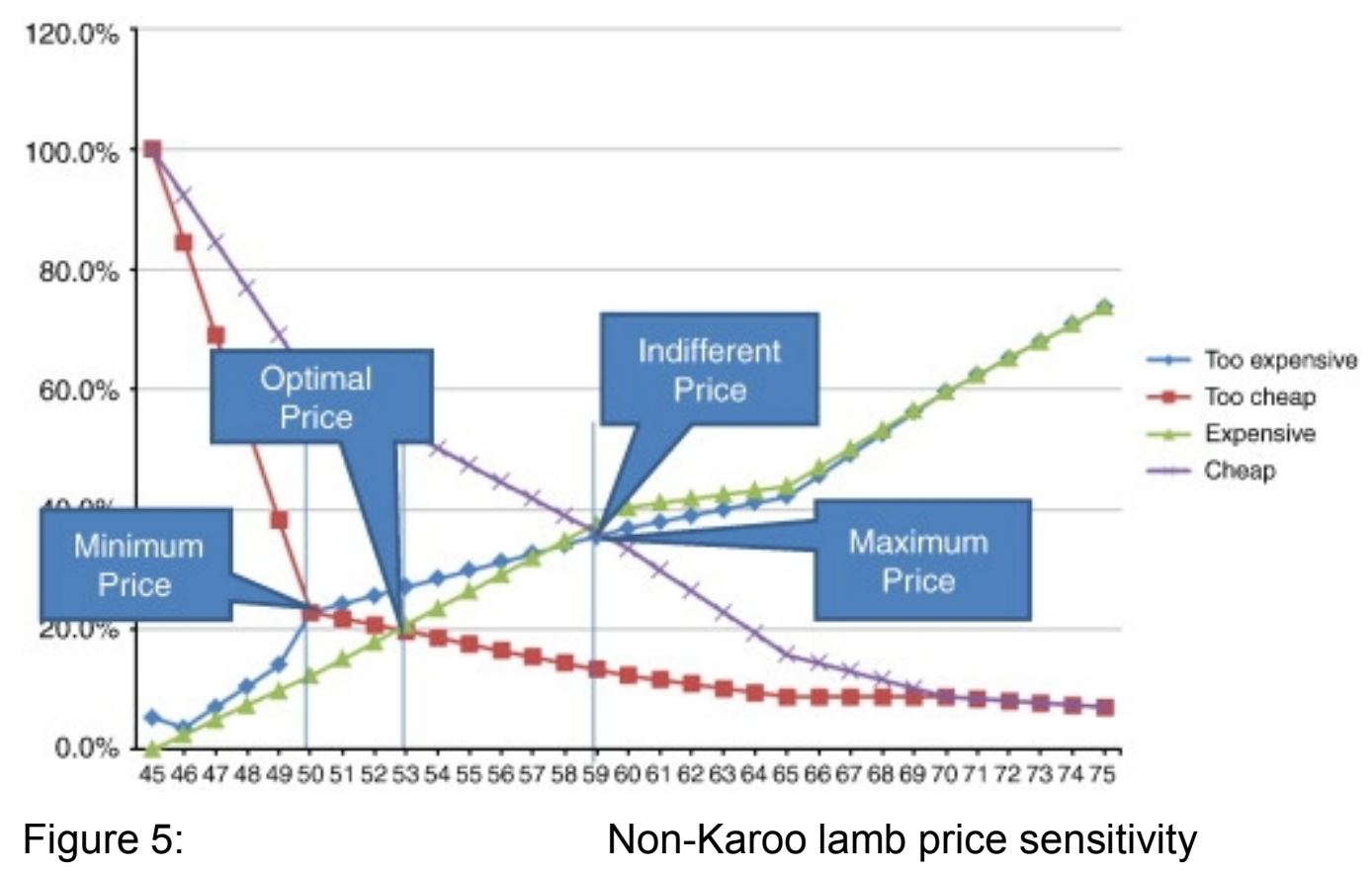

Karoo lamb consumers are willing to pay $6 \%$ more for the product of origin, whereas nonKaroo consumers have the same price for indifference as well as the maximum price they are willing to pay, illustrating their sensitivity to price. This further links non-Karoo lamb consumer's linkage of price and value for money, illustrating their extreme price sensitivity. (Fig. 4, Fig. 5, Fig. 6 and Fig. 7)

\subsection{Hierarchical Value Maps (HVM's)}

An important consideration regarding the utilization of HVM's is the determination of a cut-off level, since only associations above this cut-off level will be mapped (Leppard, Russel \& Cox, 2004). Top-down ranking was utilised in order to illustrate the most mentioned links, whereby a cut-off level of 1 signifies that only the most mentioned links will be illustrated (Leppard et al, 2004. Barrena \& Sanchez, 2009: 146). For the purpose of this research, a cut-off level of 2 was utilised in order to have a map that is easy to interpret and illustrating the two most important links to discovering consumer's perceptions of Karoo lamb.

The nodes (circles) on the HVM represent the most important attributes, consequences and values, which are scaled according to their importance. The lines connect the nodes and 
illustrate the association between the concepts, whereby the thickness illustrates the most important association.

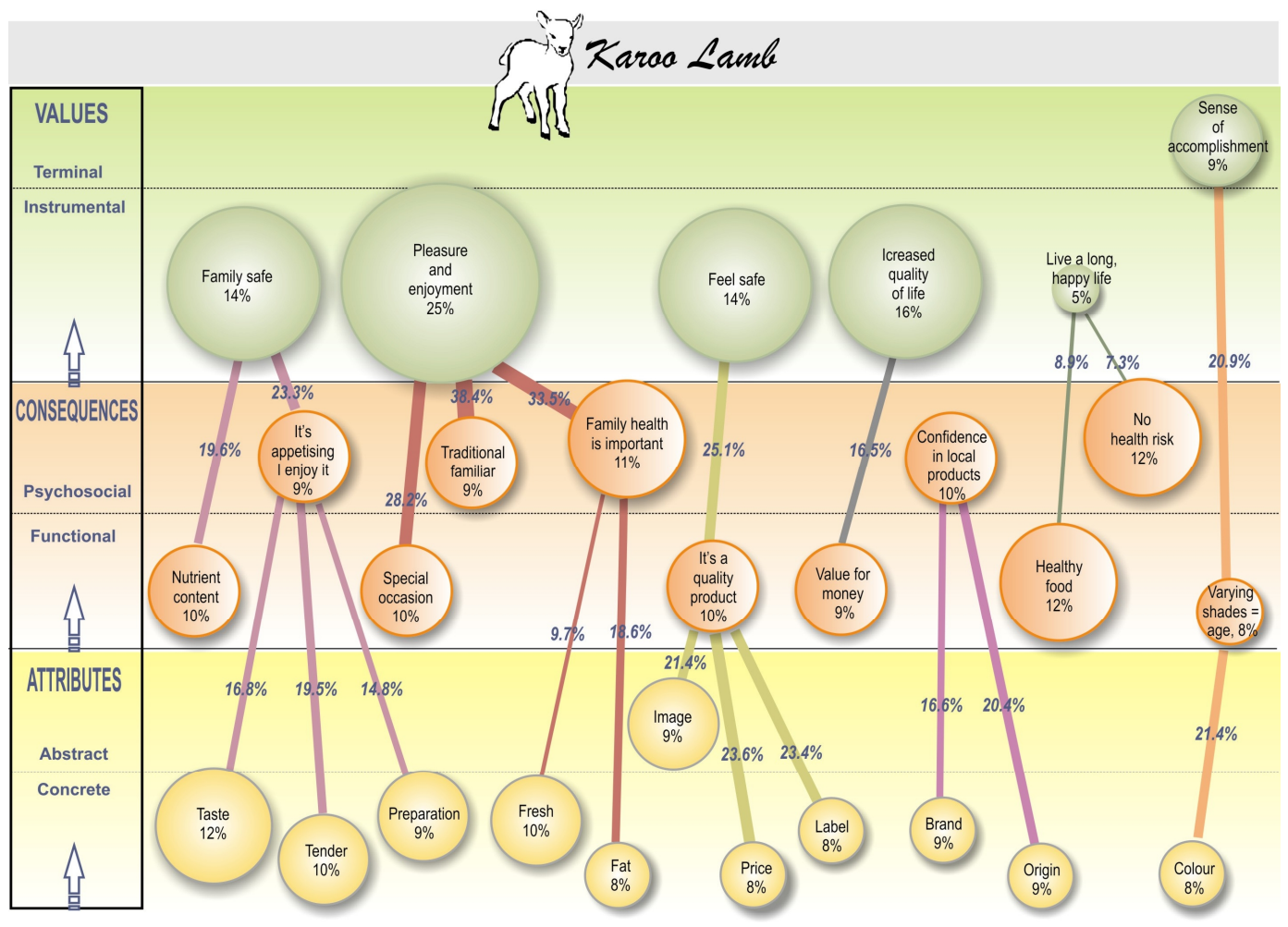

Figure 6: HVM Karoo lamb

The most important attribute for Karoo lamb was taste and for non-Karoo, taste and tenderness were most important. The most prominent and strongest link from attributes to consequences for Karoo lamb was the attributes price and label, indicative of the consequence of a quality product. This finding is crucial to the marketing and perception of Karoo lamb. For non-Karoo, a clear link between the attribute price and consequence value for money was evident and so the choice of a non-labeled product comes down to a lower price. 


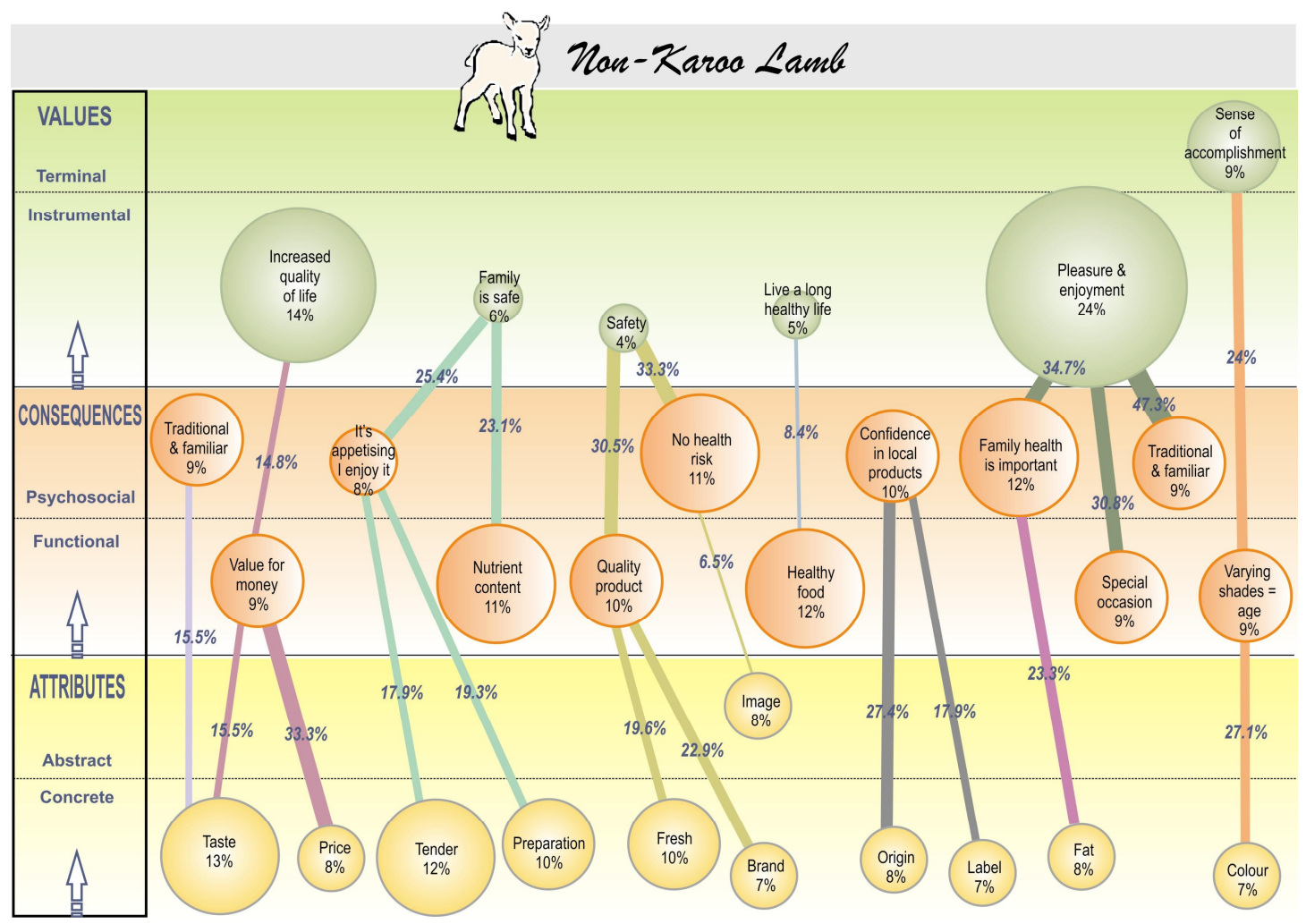

Figure 7: HVM non-Karoo lamb

\section{Conclusion}

Typically, means-end chains have been used to describe consumers' product and brand perceptions (Walker \& Olson, 1991:112). The analysis of means-end illustrates the structure of means and gives an indication as to why consumers like or do not like and buy specific products or brands (van Rekom \& Wierenga, 2007:401).

The motivational structures show perceived differences between Karoo and nonKaroo lamb consumers. Karoo lamb is preferred mainly due to its brand which signifies confidence in local produce, its taste and consequent perceived high quality. Non-Karoo lamb was seen as good value for money that satisfies the required values of consumers not interested in knowing the origin. The challenge for Karoo lamb marketers is to link their products with the attributes and consequences that make consumers differentiate Karoo lamb in their minds, in 
order to ensure that consumers will be willing to pay a premium for origin status. If this link is not achieved and successfully communicated, Karoo lamb will not be able to compete with lamb that has no origin status (non-Karoo lamb) and therefore cheaper.

Implementing origin status on Karoo lamb has cost implications. Although the margin of price difference between Karoo lamb and non-Karoo lamb willingness to purchase is not very large, there is evidence to prove that consumers are willing to pay a higher price for origin status, indicative of quality that comes from a known brand. It is clear from this study that there is a detectable notion towards the Karoo image which translates into the known product of Karoo lamb. It follows that there is scope for protection of the designation of Karoo lamb, in which consumers will be willing to pay a premium for.

\section{References}

DRAEGER, R. 2009. Measuring and analysing price sensitivity by level of product usage. Journal of Professional Pricing.

DRAEGER, R \& PERHAM, K. 2009. Pricing examples using the PSM Pricing Survey, Part 11. Journal of Professional Pricing.

LEPPARD, P, RUSSEL, CG \& COX DN. 2004. Improving means-end-chain studies by using a ranking method to construct hierarchical value map. Journal of Food Quality and Preference. 15: 489-497.

BARRENA, R \& SANCHEZ, M. 2009. Consumption frequency and degree of abstraction: A study using the laddering technique on beef consumers. Journal of Food Quality and Preference. 20: 144-155. 
HANSON, T. 2005. Understanding consumer perception of food quality: The cases of shrimps and cheese. British Food Journal. 107(7): 500-525.

BREDAHL, L. 2003. Cue utilization and quality perception with regard to branded beef. Journal of Food Quality and Preference. 15:65-75.

WALKER, BA \& OLSON, JC. 1991. Means-end chains: Connecting products with self. Journal of Business Research. 22: 111-118.

VAN REKOM, J \& WIERENGA, B. 2007. On the hierarchical nature of meansend relationships in laddering data. Journal of Business Research. 60: 401-410.

FEUNEKES, GIJ \& DEN HOED, W. 2001. Quantifying consumers' motivational strutures for food products. In: Excellence in Internal Research. The World Association of Research Professionals. Amsterdam. Netherlands.

GUTMAN, J. 1982. A Means-End Chain Model based on consumer's categorization process. Journal of Marketing. 46: 60-72.

TER HOFSTEDE, F, AUDENAERT, A, STEENKAMP, JBEM \& WEDEL, M. 1998. An investigation into the association pattern technique as a quantitative approach to measuring means-end chain. International Journal of Research in Marketing. 15: 37-50.

OLSON, JC \& REYNOLDS, TJ. 1983. Understanding consumers' cognitive structure: implication for advertising strategy. Lexington. MA: Lexington Books.

NIELSEN, NA, BECH-LARSEN, T \& GRUNERT, KG. 1998. Consumer purchase motives and product perceptions: A laddering study on vegetable oil in three countries. Journal of Food Quality and Preference. 9(6): 455-466. 
BFAB. Baseline.

LIND, LW. 2007. Consumer involvement and perceived differentiation of different kinds of pork - a Means-end Chain analysis. Journal of Food Quality and Preference. 18: 690-700. 